\title{
A pharmacokinetic analysis and dietary information are necessary to confirm or reject the hypothesis on persistent organic pollutants causing type 2 diabetes
}

\section{Tuomisto, Jouko}

2016-11-02

Tuomisto , J , Airaksinen, R, Kiviranta, H, Tukiainen, E, Pekkanen , J \& Tuomisto , J T 2016 , ' A pharmacokinetic analysis and dietary information are necessary to confirm or reject the hypothesis on persistent organic pollutants causing type 2 diabetes ' , Toxicology Letters , vol. 261 , pp. 41-48 . https://doi.org/10.1016/j.toxlet.2016.08.024

http://hdl.handle.net/10138/228492

https://doi.org/10.1016/j.toxlet.2016.08.024

publishedVersion

Downloaded from Helda, University of Helsinki institutional repository.

This is an electronic reprint of the original article.

This reprint may differ from the original in pagination and typographic detail.

Please cite the original version. 


\title{
A pharmacokinetic analysis and dietary information are necessary to confirm or reject the hypothesis on persistent organic pollutants causing type 2 diabetes
}

\author{
Jouko Tuomisto $^{\mathrm{a}, *}$, Riikka Airaksinen ${ }^{\mathrm{a}}$, Hannu Kiviranta ${ }^{\mathrm{a}}$, Erkki Tukiainen ${ }^{\mathrm{b}}$, \\ Juha Pekkanen ${ }^{\mathrm{a}, \mathrm{c}}$, Jouni T. Tuomisto ${ }^{\mathrm{a}}$ \\ ${ }^{a}$ Department of Health Protection, National Institute for Health and Welfare, Kuopio, FI-70200, Finland \\ ${ }^{\mathrm{b}}$ Department of Plastic Surgery, Helsinki University Hospital, Helsinki, Finland \\ ${ }^{\mathrm{c}}$ Department of Public Health, University of Helsinki, Finland
}

\section{H I G H L I G H T S}

- Dioxins with long half-lives accumulate throughout the entire lifetime.

- Pharmacokinetic models predict the measured concentrations in populations.

- Dioxin concentrations in the body are predicted by age, animal source food and BMI.

- Dioxins may confound the role of ample animal source food in causing diseases.

- Diet and kinetics are vital in claiming causal roles of persistent pollutants in diseases.

\section{A R T I C L E I N F O}

\section{Article history:}

Received 20 July 2016

Received in revised form 24 August 2016

Accepted 25 August 2016

Available online 26 August 2016

\section{Keywords:}

Type 2 diabetes

Persistent organic pollutant (POP)

Dioxins (PCDD/F)

Pharmacokinetics

Diet

Modeling

\begin{abstract}
A B S T R A C T
A number of studies have found an association between the concentrations of persistent organic pollutants (POP) and type 2 diabetes. Causality has remained uncertain. This study describes the pharmacokinetic behavior of PCDD/Fs (polychlorinated dibenzo-p-dioxins and dibenzofurans) both in a theoretical model based on elimination rate constants, and in a group of 409 adult surgical patients with known PCDD/F concentrations and dietary information. A model assuming $10 \%$ annual decrease in past $\mathrm{PCDD} / \mathrm{F}$ intake, predicted the measured profile of TEQ (toxic equivalents) in the patient population fairly well. The dominant determinant of PCDD/F level was age, and the level in patients was also associated with consumption of animal source products. Predicted daily intakes correlated with diet, but also with body mass index (BMI), indicating that high BMI was preceded by high consumption of foods containing PCDD/Fs. The results suggest that a third factor, e.g. high intake of animal source foods, could explain both higher levels of POPs in the body and higher incidence of type 2 diabetes, and BMI is not sufficient in describing the confounding caused by diet. Thus, to fully address the causality between POPs and type 2 diabetes, careful studies considering the pharmacokinetics of the studied compounds, and including the analysis of food consumption, are needed.
\end{abstract}

(c) 2016 Elsevier Ireland Ltd. All rights reserved.
Abbreviations: BMI, body mass index; CDD, chlorinated dibenzo-p-dioxin; CDF, chlorinated dibenzofuran; DDE, dichlorodiphenyldichloroethylene; DDT, dichlorodiphenyltrichloroethane; Hp, hepta; Hx, hexa; O, octa; PCBs, polychlorinated biphenyls; PCDD/Fs, polychlorinated dibenzo-p-dioxins and dibenzofurans; Pe, penta; POP, persistent organic pollutants; T, tetra; TCDD, 2,3,7,8-tetrachlorodibenzo-p-dioxin; TEF, toxic equivalency factor; WHO, World Health Organization; WHO-TEQ toxic equivalencies according to WHO.

* Corresponding author.

E-mail addresses: jouko.tuomisto@thl.fi, j.tuomisto@dnainternet.net (J. Tuomisto).

\section{Introduction}

A number of mainly cross-sectional studies have been published, associating persistent organic pollutants (POPs) with various diseases, particularly with type 2 diabetes (e.g. Lee et al., 2006, 2007; Rignell-Hydbom et al., 2007; Airaksinen et al., 2011; Huang et al., 2015; reviewed by Kuo et al., 2013; Taylor et al., 2013; Magliano et al., 2014; Ngwa et al., 2015). The association has been reported stronger among obese persons than among non-obese 
persons (Lee et al., 2010). A few longitudinal studies have also been published (e.g. Turyk et al., 2009; Lee et al., 2011; Wu et al., 2013; Suarez-Lopez et al., 2015; reviewed by Magliano et al., 2014; Ngwa et al., 2015). However, studies on the mechanism of action have been disappointing (Ngwa et al., 2015; Turyk et al., 2015) and often highly hypothetical (Lee and Jacobs, 2015).

There are some questions that need to be resolved, before the observed associations can be considered causal. The most obvious concerns are, first, why type 2 diabetes is increasing now although POP intakes have decreased during the last decades to $10-20 \%$ of those in 1970s (minor impact could, of course, be overwhelmed by a major factor), second, why effects of similar magnitude are reported between type 2 diabetes and a long list of POPs in completely different chemical classes such as dioxins, PCBs, and organochlorine pesticides, and third, why similar effects are seen within populations exposed to high or low POP concentrations, but not between the groups (Steenland et al., 2001; Ngwa et al., 2015). All in all, the literature is so far quite complex and confusing (Taylor et al., 2013; Ngwa et al., 2015).

In none of the studies so far a relation between the pharmacokinetics of POPs and fat intake or the amount of fat in the body was discussed. In the Ranch Hand Study, plasma concentration of TCDD (2,3,7,8-tetrachlorodibenzo-p-dioxin) was correlated with type 2 diabetes, and a closer examination of the results suggested reverse causality, i.e. imminent diabetes influencing the concentrations of TCDD (Kerger et al., 2012). The authors conclude that the absence of any significant difference in diabetes incidence between Ranch Hand veterans and comparison veterans argues against the presumption of a causal relationship between TCDD and type 2 diabetes. In other words, there was an association within each group of veterans, but no significant difference between the groups, regardless of very different plasma concentrations of TCDD. Contrary to the Ranch Hand study, no increase in type 2 diabetes was seen in the NIOSH (National Institute for Occupational Safety and Health) industrial cohort although the TCDD concentrations were almost tenfold (Steenland et al., 2001).

A thorough meta-analysis revealed that associations between diabetes and TCDD are seen in cross-sectional studies with plasma TCDD levels less than $10 \mathrm{pg} / \mathrm{g}$ lipid, but not in cohort studies with much higher TCDD levels (Goodman et al., 2015). It was concluded that the available data do not indicate a causal relationship (Goodman et al., 2015).

Thus, the requirements of Bradford Hill criteria of causality are not yet met (Hill, 1965), and the observed associations might rather suggest that TCDD serves as a proxy of something else that correlates with type 2 diabetes.

In some studies, reverse correlation - type 2 diabetes changing the pharmacokinetics of POPs - has been discussed (Longnecker and Daniels 2001; Lee et al., 2010), but it has not been considered that the higher levels of POPs in the body and higher incidence of type 2 diabetes could both be correlated with and possibly caused by a same third factor. The possibility was qualitatively hinted in the review of Taylor et al. (2013), but not quantitatively discussed. A recent review commented that findings are equivocal, and goodquality research is urgently needed (Jaacks and Staimez, 2015).

Another related recent hypothesis is that POPs might contribute to the "obesity epidemic" (Reaves et al., 2015). There is indeed an association between some but not all POPs and body mass index (BMI) or waist circumference (Elobeid et al., 2010; Dirinck et al., 2011), although generally the correlations are poor and the main determinant of POPs is age (Hue et al., 2007). It is hard to tell only on basis of associations which is the cause and which is the effect, or if both are caused by the same third factor. There is some evidence that the quality and not only quantity of food are involved. Less healthy food choices (Keski-Rahkonen et al., 2007) and increased meat consumption (Zazpe et al., 2011; Fogelholm et al., 2012) are associated with obesity. Obesity has been convincingly associated with type 2 diabetes (Ley et al., 2014); in fact in Finland nine of ten diabetics are overweight (BMI > 25, Pajunen et al., 2012). On the other hand, obesity has been associated with epigenetic transgenerational effects (Lind et al., 2016). One-generation delay could perhaps explain why the association is seen now although the concentrations of POPs were highest during 1970s and 1980s. If that is true, the effect should wane in near future.

We have previously published a case-control study on the association between soft tissue sarcoma and PCDD/Fs (polychlorinated dibenzo-p-dioxins and dibenzofurans) (Tuomisto et al., 2004). In this study, subcutaneous fat samples were collected from 954 patients with soft tissue sarcomas or controls undergoing appendicitis operation, and PCDD/Fs were analyzed. Patients also filled in a questionnaire asking a number of variables, including their dietary habits, weight history, and chemical exposure. This study material allows us to study in detail the influence of various factors on the concentrations of PCDD/Fs in fat.

The most obvious determinant of any congener concentration in the study was age (Tuomisto et al., 2004, 2005; Kiviranta et al., 2005), and in fact the concentrations were higher than expected in older age groups. This was interpreted as indicating carry-over from higher intake levels in the past (Tuomisto et al., 2004). Decreasing concentrations have in fact been clearly shown by actual measurements of PCDD/F and PCB levels in the population (Kiviranta et al., 1999; Lignell et al., 2009), as well as in various food items in Finland (Kiviranta et al., 2001) and in other countries (Liem et al., 2000). On this background, we have now modeled the kinetics of relevant PCDD/Fs using general laws of pharmacokinetics and compared the theoretical behavior of the compounds to measured values on population level and in some specific groups.

In short, we argue that causal conclusions on POPs and type 2 diabetes cannot be drawn until it is excluded that both of them might be caused by a same third factor, for example diet rich in red meat (Ley et al., 2014), or conversely, lack of fruit, vegetables, and other plant products in the diet, and until the pharmacokinetic properties of POPs are considered. In fact the pharmacokinetic considerations will be valid not only for diabetes, but for any health outcome associated with POPs.

\section{Material and methods}

\subsection{Analysis of variables of the sarcoma study}

A detailed description of sample collection and PCDD/F analysis has been given in the previous papers (Tuomisto et al., 2004; Kiviranta et al., 2005).

Briefly, sarcoma patients attended the University hospitals of Helsinki, Kuopio, Turku and Tampere. All patients over 15 years of age operated for soft tissue sarcoma between June 1997 and December 1999 were eligible as cases. Patients over 15 years of age and operated due to appendicitis in any study hospital from the same catchment area were eligible as controls. Informed consent was obtained from all patients in writing before the operation, and the study was duly approved by the ethics committees. The total number of patients recruited was 972, and after exclusion of some patients for technical reasons (e.g. too small sample, see Tuomisto et al., 2004), data on 954 patients (148 cases and 806 controls) were available. Because we did not find a significant difference in $\mathrm{PCDD} / \mathrm{F}$ concentrations between the patients and controls, the disease status was ignored for the purposes of the present study.

A subcutaneous fat sample obtained during an appendectomy or sarcoma operation was analyzed for 17 PCDD/F congeners using gas chromatography-mass spectrometry (Vartiainen et al., 1997) 
at the Laboratory of Chemistry of the National Public Health Institute of Finland (currently Chemicals and Health Unit of the National Institute for Health and Welfare), which is an accredited testing laboratory (Centre for Metrology and Accreditation code T077, EN ISO/IEC 17025). The scope of the accreditation covers the determination of $\mathrm{PCDD} / \mathrm{Fs}$ in human samples. The laboratory participates regularly in interlaboratory exercises. All analytical work was performed blind and strict quality assurance measures were undertaken.

For the purposes of the present study, all patients whose PCDD/ Fs were analyzed, and who had adequately filled in the questionnaire $(\mathrm{N}=409,43 \%)$ were selected. Patients were asked detailed information about socio-economic and lifestyle factors including dietary information, and chemical exposures, as well as their height and weight and weight changes. Consumption of various food items was asked as frequency of use. BMI was calculated as weight in kilograms divided by the square of height in meters (Quetelet, 1869).

The patients $(\mathrm{N}=409)$ were divided into three groups based on consumption frequency of fish, meat and dairy products. The three groups were low $(\mathrm{N}=131)$, moderate $(\mathrm{N}=162)$, and high $(\mathrm{N}=116)$. The food items were weighted to reflect the importance of various PCDD/F sources in Finland, 80\% fish, 10\% meat, and 10\% dairy products. It should be noted that this distribution would be different for different countries. The assumption was that at the same level of energy intake, low consumption of these items indicates high consumption of plant derived products, and vice versa. The principles of dividing to groups are presented in Supplementary material (Fig. S1).

\subsection{Modeling the accumulation of PCDD/Fs in body fat}

We modeled the expected PCDD/F concentrations in the population assuming adult exposures from ages 15-65 years in two scenarios, low and high past daily intake. Based on a marketbasket study, the average intake of PCDD/Fs in Finland in 19982000 (close to the timing of the soft tissue sarcoma study) was 53$68 \mathrm{pg} /$ day (Kiviranta et al., 2004). Thus, the low and high doses selected for modeling were $30 \mathrm{pg} /$ day and $120 \mathrm{pg} /$ day (as TEQ, see Table 1) as an example of extremes. These doses were split to intakes of each individual congener using the congener distribution in the Finnish diet (Kiviranta et al., 2004). We modeled an intake ending at $30 \mathrm{pg} /$ day and $120 \mathrm{pg} /$ day (TEQ), but starting 50 years earlier at a higher level, integrated backwards assuming a $10 \%$ annual decrease in intake. This is close to the observed decline in dioxin and PCB concentrations in Finnish population (Kiviranta et al., 1999), and decrease in concentrations in Baltic fish (Airaksinen et al., 2014). Thus the range of the study is approximately $1950-2000$.

This results in the following models. If both the body weight (amount of fat) and PCDD/F intake are stable, concentration in body fat is derived as follows (Goldstein et al., 1974):

$\mathrm{C}=\mathrm{D}^{*}\left(1-\mathrm{e}^{-\mathrm{k}^{*} \mathrm{t}}\right) / \mathrm{V} / \mathrm{k}$

$\mathrm{C}=$ concentration $(\mathrm{pg} / \mathrm{g}$ in fat $)$

$\mathrm{D}=$ intake dose $(\mathrm{pg} / \mathrm{year})$

$\mathrm{k}=$ elimination constant $(1 /$ year $)$

$\mathrm{V}=$ distribution volume (amount of body fat, $\mathrm{kg}$ )

$\mathrm{t}=$ time of exposure (years)

Assuming a gradual decrease in past intake, the formula to predict concentrations at various ages is:

$C_{\mathrm{n}}=\mathrm{D}_{\mathrm{n}}{ }^{*}\left(1-\mathrm{e}^{-(\mathrm{r}+\mathrm{k})^{*} \mathrm{t}}\right) / \mathrm{V}_{\mathrm{n}} /(\mathrm{r}+\mathrm{k})$

$\mathrm{C}_{\mathrm{n}}=$ concentration now, integrated over the whole exposure period assuming a decreasing dose rate (pg/g in fat)

$D_{n}=$ intake dose now (pg/year)

$r=$ annual change in intake (fraction per year)

$\mathrm{k}=$ elimination constant (1/year)

Table 1

Properties of PCDD/F congeners in this study.

\begin{tabular}{|c|c|c|c|c|c|c|}
\hline Congener & $\mathrm{t}_{1} / 2$, years $^{\mathrm{a}}$ & $\mathrm{k}_{\mathrm{el}} \mathrm{a}^{-1}$ & Fraction of TEQ in diet, \% & TEF & Intake-Low, pg/day ${ }^{\mathrm{c}}$ & Intake-High, pg/day $^{\mathrm{d}}$ \\
\hline 2,3,7,8-TCDD & 7.2 & 0.096 & 9.0 & 1 & 2.7 & 11 \\
\hline $1,2,3,7,8-\mathrm{PeCDD}$ & 11.2 & 0.062 & 20 & 1 & 5.9 & 24 \\
\hline $1,2,3,4,7,8-\mathrm{HxCDD}$ & 9.8 & 0.071 & 0.89 & 0.1 & 2.7 & 11 \\
\hline $1,2,3,6,7,8-\mathrm{HxCDD}$ & 13.1 & 0.053 & 2.7 & 0.1 & 8.0 & 32 \\
\hline $1,2,3,7,8,9-\mathrm{HxCDD}$ & 5.1 & 0.14 & 0.27 & 0.1 & 0.82 & 3.3 \\
\hline $1,2,3,4,6,7,8-\mathrm{HpCDD}$ & 4.9 & 0.14 & 0.56 & 0.01 & 17 & 67 \\
\hline OCDD & 6.7 & 0.10 & 0.17 & 0.0003 & 171 & 685 \\
\hline $2,3,7,8-\mathrm{TCDF}$ & 2.1 & 0.33 & 9.7 & 0.1 & 29 & 116 \\
\hline $1,2,3,7,8-\mathrm{PeCDF}$ & 3.5 & 0.20 & 0.70 & 0.03 & 7.0 & 28 \\
\hline $2,3,4,7,8-\mathrm{PeCDF}$ & 7.0 & 0.099 & 53 & 0.3 & 53 & 213 \\
\hline $1,2,3,4,7,8-\mathrm{HxCDF}$ & 6.4 & 0.11 & 0.67 & 0.1 & 2.0 & 8.0 \\
\hline $1,2,3,6,7,8-\mathrm{HxCDF}$ & 7.2 & 0.096 & 1.1 & 0.1 & 3.2 & 13 \\
\hline $1,2,3,7,8,9-\mathrm{HxCDF}$ & 7.2 & 0.096 & 0 & 0.1 & 0 & 0 \\
\hline $2,3,4,6,7,8-\mathrm{HxCDF}$ & 2.8 & 0.25 & 1.0 & 0.1 & 3.0 & 12 \\
\hline $1,2,3,4,6,7,8-\mathrm{HpCDF}$ & 3.1 & 0.22 & 0.51 & 0.01 & 15 & 62 \\
\hline $1,2,3,4,7,8,9-\mathrm{HpCDF}$ & 4.6 & 0.15 & 0 & 0.01 & 0 & 0 \\
\hline OCDF & 1.4 & 0.50 & 0.0089 & 0.0003 & 8.9 & 36 \\
\hline
\end{tabular}

a From Milbrath et al., 2009.

b From Kiviranta et al., 2004.

c Assuming total TEQ intake of $30 \mathrm{pg} /$ day.

d Assuming total TEQ intake of $120 \mathrm{pg} /$ day. 
$\mathrm{t}=$ duration of adult exposure (years); age of a patient is 15 years $+\mathrm{t}$

$\mathrm{V}_{\mathrm{n}}=$ distribution volume now (amount of body fat, $\mathrm{kg}$ )

The concentrations of each PCDD/F congener, as pg/g fat were calculated assuming a distribution volume of $20 \mathrm{~kg}$, and the sum of PCDD/Fs was calculated as TEQ by using the 2005 WHO toxic equivalency factors (van den Berg et al., 2006). The half-lives from Milbrath et al. (2009) were used.

\subsection{Modeling the intake of $P C D D / F$ in patients}

The starting point of the model was the present concentrations of PCDD/Fs $\left(C_{n}\right)$ in fat, age, and distribution volume $\left(V_{n}\right)$, which was calculated individually based on sex, present BMI and age (Deurenberg et al., 1991). In addition, duration of exposure ( $t$ ) was calculated from 15 years to present age. This information was used for the following formula to estimate the intake of each $\mathrm{PCDD} / \mathrm{F}$ congener for each patient:

$\mathrm{D}_{\mathrm{n}}=\mathrm{C}_{\mathrm{n}}{ }^{*} \mathrm{~V}_{\mathrm{n}}{ }^{*}(\mathrm{r}+\mathrm{k}) /\left(1-\mathrm{e}^{-(\mathrm{r}+\mathrm{k})^{*} \mathrm{t}}\right)$

As above, the sum intake of PCDD/Fs was calculated as TEQ by using the 2005 WHO toxic equivalency factors (van den Berg et al., 2006) for each patient.

Derivation of these formulas can be found at (accessed Aug 24, 2016)

http://en.opasnet.org/w/Human_PBPK_model_for_dioxin\#Tuomisto_et_al

\section{Results}

\subsection{Modeling the accumulation of $P C D D / F s$}

Fig. 1. demonstrates the increase of selected PCDD/F congeners assuming a constant intake of $10 \mathrm{pg} /$ day for each of them, constant elimination, and stable distribution volume of $20 \mathrm{~kg}$ during 50 years of adult life (Eq. (1)). A steady state is achieved in 50 years for most but not all congeners, and at different rates due to different half-lives. The graph also demonstrates that congeners with long half-lives (e.g. 1,2,3,6,7,8-HxCDD, 13.1 years) reach much higher concentrations at similar intake levels than congeners with short half-lives (e.g. 2,3,7,8-TCDF, 2.1 years).

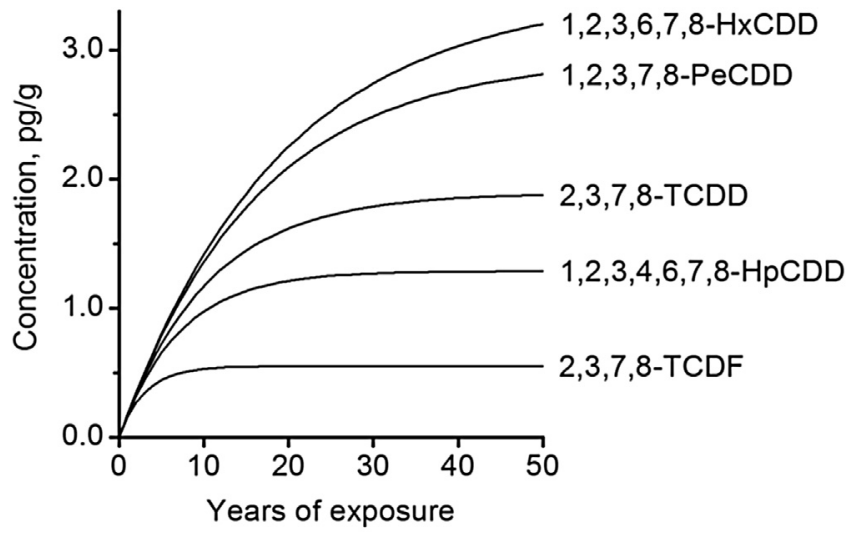

Fig. 1. Simple prospective model of the concentrations in fat of selected $\mathrm{PCDD} / \mathrm{F}$ congeners during 50 years of adult life, assuming zero concentration at start, a constant intake of $10 \mathrm{pg} /$ day of each $\mathrm{PCDD} / \mathrm{F}$, constant elimination, and stable distribution volume (Eq. (1)).
When modeling the concentrations in a real population, the observed decrease in PCDD/F intake during the last decades must be taken into account. Fig. 2. shows the modeled concentrations of PCDD/Fs as TEQ in a population of various ages (15-65 years). The present daily intake $\left(D_{n}\right)$, was assumed to be either $30 \mathrm{pg}$ (low exposure) or $120 \mathrm{pg}$ (high exposure), split to intakes of each individual congener using the congener distribution in the Finnish $\operatorname{diet}$ (Table 1; Kiviranta et al., 2004). The earlier higher intakes were modeled assuming a $10 \%$ annual decrease $(r=-0.1 /$ year $)$. A stable distribution volume $\left(\mathrm{V}_{\mathrm{n}}\right)$ of $20 \mathrm{~kg}$, and an unchanged elimination constant (k) were assumed (Eq. (2)).

The modeled concentrations of $\mathrm{PCDD} / \mathrm{F}$ TEQ did not reach a steady state level. Instead, regardless of the scenario, the concentrations in older generations are highest in an exponential manner. This pattern closely resembles the distribution of actual PCDD/F concentrations measured in the Finnish population (Tuomisto et al., 2004; Kiviranta et al., 2005; Fig. 3).

Weight gain affects PCDD/F concentrations in opposing ways. Increase of fat mass will cause dilution of PCDD/Fs. This will then slow down elimination, which is dependent on concentration rather than body burden. An increase in body weight would require higher food intake, and depending on the type of diet, PCDD/F intake would increase as well. In order to keep the model simple, a constant distribution volume of $20 \mathrm{~kg}$ was assumed, and the changes in body weight were not modeled in this exercise.

The modeling exercise highlights that age is a very important determinant of $\mathrm{PCDD} / \mathrm{Fs}$, and that in epidemiological studies regarding POPs and type 2 diabetes, the relationship between age and POP concentration should not be assumed to be linear or of any other predetermined shape. Instead, the relationship has to be assessed carefully by taking into account pharmacokinetic properties which are different for each compound.

Data on individual congeners are available in Supplementary material (Fig. S2). They predict that concentrations of compounds with a long half-life (e.g. 1,2,3,7,8-PeCDD and 1,2,3,6,7,8-HxCDD) are enhanced after longer exposure (i.e. in older generations), and congeners with a short half-life reach steady state in about ten years (e.g. 2,3,7,8-TCDF). This is understandable on the basis of the behavior of different congeners as shown in Fig. 1.

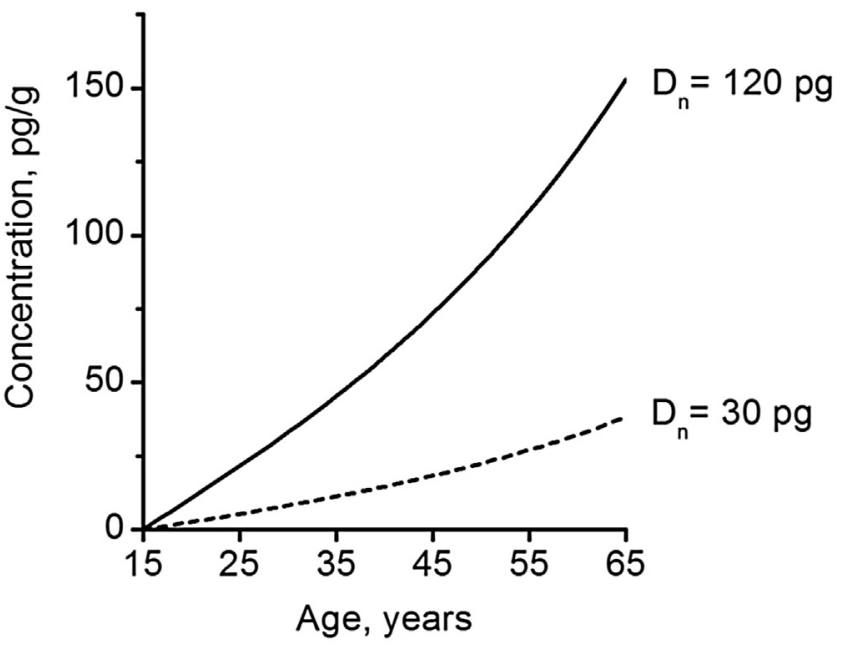

Fig. 2. Retrospective modeled concentration of $P C D D / F$ TEQ in a population at ages 15-65 years, ignoring the intake during childhood. Assumptions: 1) present intake of either 30 or $120 \mathrm{pg} /$ day, 2) high initial intake and $10 \%$ annual decrease, 3) unchanging elimination constant, and 4) stable distribution volume of $20 \mathrm{~kg}$ (Eq. (2)). Taking into account childhood dioxin intake would elevate the concentrations at the age of 15 years by about $5 \mathrm{pg} / \mathrm{g}$. 

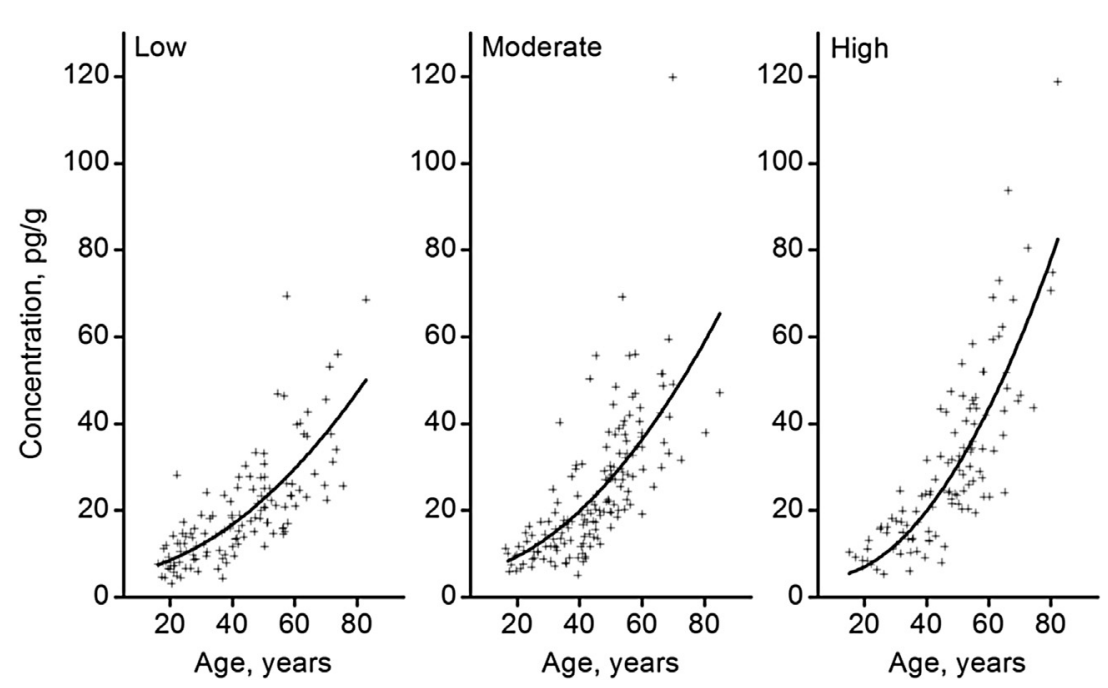

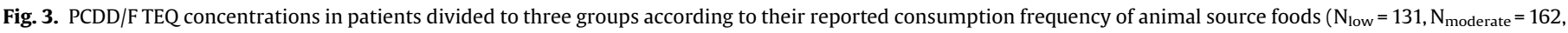

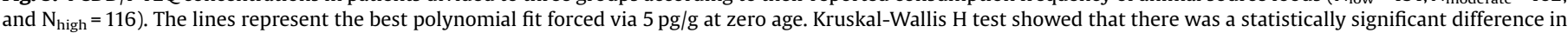
$\mathrm{PCDD} / \mathrm{F}$ concentrations between the animal source food groups $(\mathrm{p}<0.001)$.

\subsection{Actual PCDD/F concentrations in patients with different diets}

Fig. 3 illustrates the PCDD/F concentrations in the patient population by age. The patients were divided into three groups (low, moderate, high) according to their reported consumption frequency of fish, meat and dairy products. We assumed that the use of energy (e.g. due to different exercise practices) did not differ significantly among the three groups. The results illustrate that in addition to age, diet is another important determinant of PCDD/F concentrations. The highest intake group approaches the upper predicted levels (cf. Fig. 2), and the lowest intake group the lower predicted levels. It should be noted that the relatively crude classification of food preferences is likely to dilute the differences by causing some misclassification among the three groups (Fogelholm et al., 2012).

\subsection{Modeling the present $P C D D / F$ intake based on measured present and modeled past concentrations in fat}

The PCDD/F concentrations in patients were used to predict the present daily intake levels that would lead to the analyzed concentrations. The modeled intake levels were shown to vary between the three animal source food groups $(\mathrm{p}<0.001)$ although variations within groups were large (Fig. 4A). This indicates that diet is associated with the PCDD/F concentrations in the studied patient population. The modeled daily intake levels correlate reasonably well with the actual intake levels of 53-68 pg/day in Finland (Kiviranta et al., 2004) and with the modeled doses (cf. Fig. 2), validating the used parameters and equations (e.g. halflives, assumption of the decrease of concentrations over the years).

Intakes were also predicted for groups with different BMI (Fig. 4B). There is a clear increase in predicted daily intake with increasing BMI.

\section{Discussion}

More than 20 cross-sectional studies and about ten longitudinal studies have been published on the association of POPs and type 2 diabetes (reviewed by eg. Magliano et al., 2014; Ngwa et al., 2015). Surprisingly, the impact of dietary factors has not been discussed in detail in any of those studies, even though it is an obvious confounding factor (Taylor et al., 2013; Magliano et al., 2014). To

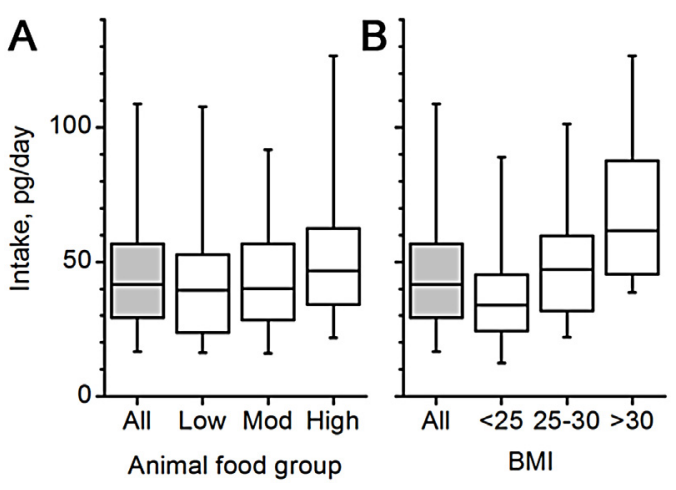

Fig. 4. Modeled daily intake of PCDD/Fs (Eq. (3)) grouped (A) according to reported consumption frequency of fish, meat, and dairy products $\left(N_{\text {low }}=131, N_{\text {moderate }}=162\right.$, and $\left.\mathrm{N}_{\text {high }}=116\right)$, and $(\mathrm{B})$ according to their BMI $\left(\mathrm{N}_{\mathrm{BMI}<25}=213, \mathrm{~N}_{\mathrm{BMI} 25-30}=147\right.$, and $\mathrm{N}_{\mathrm{BMI}>30}=49$ ). Present PCDD/F level, present distribution volume, time between 15 years' age and present, and elimination constant of each individual congener were used to calculate the dose assuming a $10 \%$ annual decrease in concentrations. Individual congener doses were then transformed to TEQ doses of each patient. The boxes represent the median and $25-75 \%$ percentiles and the whiskers represent the 5-95\% percentiles. Kruskal-Wallis $\mathrm{H}$ test showed that there was a statistically significant difference in $\mathrm{PCDD} / \mathrm{F}$ intake between the animal source food groups $(\mathrm{p}<0.001)$, as well as BMI groups $(\mathrm{p}<0.001)$.

put it simply, eating more increases the body burden of POPs, particularly eating animal source foods.

It is interesting in this context that a so-called "prudent" diet rich in fruit and vegetables - seems to be associated with a reduced risk of type 2 diabetes, even when adjusted for BMI, and a "conservative" pattern diet - rich in potatoes, red meat and whole milk - is associated with elevated risk of type 2 diabetes (Montonen et al., 2005). Recent reviews also concluded that red and processed meats are risk factors of type 2 diabetes, not only of cardiovascular disease (Micha et al., 2012; Ley et al., 2014).

Dioxin and PCB intake in most countries is almost exclusively from diet, mostly via animal fat (Liem et al., 2000; Hallikainen and Vartiainen, 1997; Kiviranta et al., 2001, 2004; Knutsen et al., 2011). Human consumption of fat is variable, but the average in Finland in 2002 was estimated at $87 \mathrm{~g} /$ day in males and $59 \mathrm{~g} /$ day in females (Männistö et al., 2003), resulting in 22-33 kg/year and 1300$1800 \mathrm{~kg}$ during adult lifetime. This means that roughly $99 \%$ of the consumed fat is burned down, even assuming that $10-20 \mathrm{~kg}$ of 
weight is typically gained during adulthood, although variation is large. If there is no weight gain, fat is burned down at the same rate it is consumed. However, POPs are eliminated much more slowly than the fat they are stored in. Thus, any slowly eliminating POPs derived from dietary fat are highly concentrated in the adipose tissue during the lifetime. Since age is so dominant, and diet and weight changes are so diverse, yet strongly linked to POP accumulation, interpretation of possible associations between POPs and diseases at population level becomes challenging.

Excessive energy intake results in obesity, but depending on the energy source, not necessarily in increased POP accumulation. If obesity is caused by excessive intake of animal fat and foods of animal origin, POP concentrations in the adipose tissue tend to be higher than if the weight has been gained by excessive consumption of carbohydrates and foods of plant origin, as shown by the present study. If weight is gained by excessive carbohydrate intake, the amount of fat will increase, but since POP levels in foods of plant origin are usually very low, POP intake is also likely to be low. This means that not only the quantity but also the quality of the diet is highly important for both the body burdens and concentrations of POPs, and that in studies addressing the POPdiabetes association, BMI alone is not sufficient in describing the confounding caused by diet. Also, as commented by RignellHydbom et al. (2007), if a diabetic patient deliberately reduces weight after the diagnosis, concentration increases due to decreased volume of distribution.

The pharmacokinetics of POPs are influenced by two opposite forces: the dilution effect caused by an increase in body fat, and slower rate of elimination due to this dilution. Excessive fat consumption results in obesity, but because fats are eliminated faster than POPs, the latter are concentrated in the adipose tissue. The increased amount of body fat will dilute the POPs in fat, but by the same token, POP elimination is slowed down, because the free concentration available to metabolism and excretion is also decreased. This opposes the dilution effect.

If weight gain is due to excessive carbohydrate intake, the body burden of POPs might remain stable compared with the situation without body weight increase, or only increase slightly due to lower levels available for elimination. However, because of increasing distribution volume, the concentrations would decrease. Due to the complexity of the issue, resulting concentrations can only be revealed by careful pharmacokinetic analysis also appreciating the different half-lives of different compounds. The present results indicate that higher proportion of animal fat in diet has led to increased PCDD/F concentrations in patients, even if the higher fat volume causes a dilution effect.

An interesting study using NHANES material implies that type 2 diabetes risk associated with serum PCB concentrations is lower in groups with high serum carotenoid concentrations (Hofe et al., 2014). This was interpreted to indicate that carotenoids prevent the risk of type 2 diabetes caused by PCB-compounds. However, the carotenoid concentrations are also a proxy of high vegetable diet (Hofe et al., 2014). More vegetables in diet, at similar energy intake level, means relatively less animal source products (Fogelholm et al., 2012). This would mean lower PCB intake, but also confounding by the type of diet. It is also interesting that in a large meta-analysis neither fish consumption nor eicosapentaenoic acid (EPA) or docosahexaenoic acid (DHA) intake were associated with type 2 diabetes, but alpha-linolenic acid was associated with a nonsignificant trend toward lower risk (Wu et al., 2012). This could also simply indicate the effect of a plant-dominated diet. The same metaanalysis also shows the large variability between studies which increases the risk of publication bias.

Consideration of dietary and kinetic factors is important, because as Taylor et al. (2013) discussed, the data so far do not confirm causality. In their analysis the strongest positive correlation of type 2 diabetes with POPs occurred with such diverse compounds as trans-nonachlor, DDE (major DDT metabolite), some PCBs and PCDD/Fs, less so with other compounds such as perfluoroalkyl acids and brominated compounds. It is confusing that in some studies type 2 diabetes associates with PCBs but not dioxins (Lee et al., 2010), in dioxin-like, but not non-dioxin-like PCBs (Lee et al., 2007; Hofe et al., 2014), in some studies with DDT metabolites but not PCBs (Rignell-Hydbom et al., 2007; Turyk et al., 2009). Dose-response curves vary in different studies, and even the same group finds a monotonic and additive dose response in one study (Lee et al., 2006), and an inverse U-type dose response in another (Lee et al., 2010).

Whereas different chemical groups have been implicated regardless of their completely different mechanisms of action, it is difficult to link them to a common etiologic mechanism (Taylor et al., 2013). Thus, only affinity to fat and slow elimination seem to be common to all of them. It is interesting that among PCB congeners, the long persistency correlates best with type 2 diabetes (Lee et al., 2010, 2011; Magliano et al., 2014). This agrees with that high POP concentrations might serve as a proxy for the life-long consumption of high-fat animal products, and the association between POPs and diabetes would not be causal.

It is noteworthy that there is little evidence for an association between diabetes and polybrominated biphenyls (PBB), polybrominated diphenylethers (PBDE) and perfluoroalkyl acids (Vasiliu et al., 2006; Airaksinen et al., 2011; Taylor et al., 2013; Magliano et al., 2014; Ngwa et al., 2015). Their intake is not mainly from food but from other sources (Schecter et al., 2006; Sahlstrom et al., 2015; Taylor et al., 2013), i.e. only compounds in food associate with type 2 diabetes.

The risk ratios among the groups are fairly similar, regardless of whether the group is a high-exposure group due to accidental or industrial exposure (PCDD/F 1-5.1, PCB 1-6.8, DDE 1-1.86, Magliano et al., 2014; Ngwa et al., 2015) or a group from general population (PCDD/F 1-2.7, PCB 1-15.7, DDE 1-12.7, in one study 139.4!, Magliano et al., 2014; Ngwa et al., 2015). This agrees with the long half-life as being their most important common denominator.

Thus a correlation between POPs and a disease could also be interpreted so that elevated POPs only indicate increased animal fat consumption, perhaps resulting in obesity, which could be the true risk factors. High intake of meat seems to predict weight gain (Fogelholm et al., 2012). On the other hand, if obesity is based largely to carbohydrate excess (or low-dioxin vegetable oils), POP concentrations might be expected to be low. At any rate, energy expenditure and food consumption associate with BMI (Madden et al., 2016), and thus POP intake in those individuals with higher BMI has also been higher than average. There is also direct evidence that meat consumption associates with type 2 diabetes (Micha et al., 2012; Ley et al., 2014). Therefore detailed consideration of pharmacokinetic factors as well as diet may be necessary before any conclusions on causality. This could be best achieved in prospective studies with both individual POP concentrations and individual food preferences known. Unfortunately this information is rarely available so far, and thorough studies may be recommended.

Animal studies are very few, but some descriptive studies have been published in which more or less contaminated fish oil was included in mouse or rat diet (Ruzzin et al., 2010; Ibrahim et al., 2011). These imply a causal association between POPs and insulin resistance and obesity, but so far do not indicate a clear mechanism. Controlled animal studies with mechanistic orientation would clearly benefit the attempts to interpret the epidemiological findings.

There are some weaknesses in the present study. As beautifully shown by a review of Fogelholm et al. (2012) even showing a 
causality of major nutrients or food items in increasing or decreasing the risk of weight gain is extremely difficult. On the other hand, it is probable that meat consumption is associated with weight increase, and independently with type 2 diabetes (Fogelholm et al., 2012; Ley et al., 2014). There is good evidence that meat is an important source of dioxins (Liem et al., 2000). Fish and dairy do not increase the risk of type 2 diabetes (Ley et al., 2014), but the purpose now was to study the effects of diet on POP concentrations, not type 2 diabetes directly. Because main sources vary, the situation might be different in different countries. Changes in body weight were not taken into account at this stage, although we are planning to model it as well. Food frequency questioning has its limitations, and our questionnaire was not originally planned for the present use. However, this would probably only dilute the effects (Fogelholm et al., 2012), which might lessen the differences between the groups. Models (Figs. 2 and 4) are relatively sensitive to assumptions, and 10\% annual decrease that best predicts the results, is somewhat higher than that estimated in most studies (e.g. 5-6\% in Kiviranta et al., 1999). Even if our predictions are crude, they clearly emphasize the importance of taking into account diet and weight changes before concluding that associations between POP concentrations and type 2 diabetes are causal. We plan to extend this analysis to the clinical data on individual PCDD/F and PCB congeners which have quite different kinetic properties including tenfold differences in elimination rates.

In conclusion, the present study clearly demonstrates some pitfalls of associations between diseases and POP concentrations, especially in cross-sectional studies, but even in prospective cohorts. Because POP compounds accumulate slowly from diet, and have long half-lives, a thorough understanding of their kinetic behavior during decades and related to diet is needed, before any conclusions of their causative role in slowly developing diseases have a sound scientific basis. Thus a thorough pharmacokinetic analysis will be needed to strengthen the plausibility of any claims that obesity or type 2 diabetes would be causally related to POP levels.

\section{Conflicts of interest}

None.

\section{Acknowledgements}

This work was supported by European Commission; Grant number: ENV-CT96-0336, QLK4-1999-01446; and Academy of Finland; Grant number: 77298.

\section{Appendix A. Supplementary data}

Supplementary data associated with this article can be found, in the online version, at http://dx.doi.org/10.1016/j. toxlet.2016.08.024.

\section{References}

Airaksinen, R., Rantakokko, P., Eriksson, J.G., Blomstedt, P., Kajantie, E., Kiviranta, H., 2011. Association between type 2 diabetes and exposure to persistent organic pollutants. Diabetes Care 34, 1972-1979.

Airaksinen, R., Hallikainen, A., Rantakokko, P., Ruokojärvi, P., Vuorinen, P.J., Parmanne, R., Verta, M., Mannio, J., Kiviranta, H., 2014. Time trends and congener profiles of PCDD/Fs, PCBs, and PBDEs in Baltic herring off the coast of Finland during 1978-2009. Chemosphere 114, 165-171.

Deurenberg, P., Weststrate, J.A., Seidell, J.C., 1991. Body mass index as a measure of body fatness: age- and sex-specific prediction formulas. Br. J. Nutr. 65, 105-114.

Dirinck, E., Jorens, P.G., Covaci, A., Geens, T., Roosens, L., Neels, H., Mertens, I., van Gaal, L., 2011. Obesity and persistent organic pollutants: possible obesogenic effect of organochlorine pesticides and polychlorinated biphenyls. Obesity 19, 709-714.
Elobeid, M.A., Brock, D.W., Allison, D.B., Padilla, M.A., Ruden, D.M., 2010. Endocrine disruptors and obesity: an examination of selected persistent organic pollutants in the NHANES 1999-2002 data. Int. J. Environ. Res. Public Health 7, 2988-3005.

Fogelholm, M., Anderssen, S., Gunnarsdottir, I., Lahti-Koski, M., 2012. Dietary macronutrients and food consumption as determinants of long-term weight change in adult populations: a systematic literature review. Food Nutr. Res. 56 (19103) doi:http://dx.doi.org/10.3402/fnr.v56i0.19103.

Goldstein, A., Aronow, L., Kalman, S.M., 1974. The time course of drug action, Principles of Drug Action: The Basis of Pharmacology. 2 ed. John Wiley \& Sons, New York, pp. 301-338.

Goodman, M., Narayan, K.M.V., Flanders, D., Chang, E.T., Adami, H.O., Boffetta, P., Mandel, J.S., 2015. Dose-response relationship between serum 2,3,7,8tetrachlorodibenzo-p-dioxin and diabetes mellitus: a meta-analysis. Am. J. Epidemiol. 181, 374-384.

Hallikainen, A., Vartiainen, T., 1997. Food control surveys of polychlorinated dibenzo-p-dioxins and dibenzofurans and intake estimates. Food Addit Contam $14,355-366$.

Hill, A.B., 1965. The environment and disease: association or causation? Proc. R. Soc. Med. 295-300.

Hofe, C.R., Feng, L., Zephyr, D., Stromberg, A.J., Hennig, B., Gaetke, L.M., 2014. Fruit and vegetable intake, as reflected by serum carotenoid concentrations, predicts reduced probability of polychlorinated biphenyl-associated risk for type 2 diabetes: national health and nutrition examination survey 2003-2004. Nutr. Res. 34, 285-293.

Huang, C.Y., Wu, C.L., Yang, Y.C., Jung-Wei Chang, J.W., Kuo, Y.C., Cheng, Y.Y., Wu, J.S., Lee, C.C., Guo, H.R., 2015. Association between dioxin and diabetes mellitus in an endemic area of exposure in Taiwan. A population-based study. Medicine 94 (42), e1730.

Hue, O., Marcotte, J., Berrigan, F., Simoneau, M., Doré, J., Marceau, P., Marceau, S., Tremblay, A., Teasdale, N., 2007. Plasma concentration of organochlorine compounds is associated with age and not obesity. Chemosphere 67, 1463-1467.

Ibrahim, M.M., Fjære, E., Lock, E.J., Naville, D., Amlund, H., Meugnier, E., Battistoni, B. L.M., Frøyland, L., Madsen, L., Jessen, N., Lund, S., Vidal, H., Ruzzin, J., 2011. Chronic consumption of farmed Salmon containing persistent organic pollutants causes insulin resistance and obesity in mice. PLoS One 6 (9), e25170.

Jaacks, L.M., Staimez, L.R., 2015. Association of persistent organic pollutants and non-persistent pesticides with diabetes and diabetes-related health outcomes in Asia: a systematic review. Environ. Int. 76, 57-70.

Kerger, B.D., Scott, P.K., Pavuk, M., Gough, M., Paustenbach, D.J., 2012. Re-analysis of Ranch Hand study supports reverse causation hypothesis between dioxin and diabetes. Crit. Rev. Toxicol. 42, 669-687.

Keski-Rahkonen, A., Bulik, C.M., Pietiläinen, K.H., Rose, R.J., Kaprio, J., Rissanen, A., 2007. Eating styles, overweight and obesity in young adult twins. Eur. J. Clin. Nutr. 61, 822-829.

Kiviranta, H., Purkunen, R., Vartiainen, T., 1999. Levels and trends of PCDD/Fs and PCBs in human milk in Finland. Chemosphere 38, 311-323.

Kiviranta, H., Hallikainen, A., Ovaskainen, M.L., Kumpulainen, J., Vartiainen, T., 2001. Dietary intakes of polychlorinated dibenzo-p-dioxins, dibenzofurans and polychlorinated biphenyls in Finland. Food Addit. Contam. 18, 945-953.

Kiviranta, H., Ovaskainen, M.L., Vartiainen, T., 2004. Market basket study on dietary intake of PCDD/Fs, PCBs, and PBDEs in Finland. Environ. Int. 30, 923-932.

Kiviranta, H., Tuomisto, J.T., Tuomisto, J., Tukiainen, E., Vartiainen, T., 2005. Polychlorinated dibenzo-p-dioxins, dibenzofurans, and biphenyls in the general population in Finland. Chemosphere 60, 854-869.

Knutsen, H.K., Kvalem, H.E., Haugen, M., Meltzer, H.M., Brantsæter, A.L., Alexander, J., Päpke, O., Liane, V.H., Georg Becher, G., Thomsen, C., 2011. Sex, BMI and age in addition to dietary intakes influence blood concentrations and congener profiles of dioxins and PCBs. Mol. Nutr. Food Res. 55, 772-782.

Kuo, C.C., Moon, K., Thayer, K.A., Navas-Acien, A., 2013. Environmental chemicals and type 2 diabetes: an updated systematic review of the epidemiologic evidence. Curr. Diabetes Rep. 13, 831-849.

Lee, D.H., Jacobs Jr., D.R., 2015. Hormesis and public health: can glutathione depletion and mitochondrial dysfunction due to very low-dose chronic exposure to persistent organic pollutants be mitigated? J. Epidemiol. Commun. Health 69, 294-300.

Lee, D.H., Lee, I.K., Song, K., Steffes, M., Toscano, W., Baker, B.A., Jacobs Jr., D.R., 2006. A Strong dose-response relation between serum concentrations of persistent organic pollutants and diabetes. Diabetes Care 29, 1638-1644.

Lee, D.H., Lee, I.K., Steffes, M., Jacobs Jr., D.R., 2007. Extended analyses of the association between serum concentrations of persistent organic pollutants and diabetes. Diabetes Care 30, 1596-1598.

Lee, D.H., Steffes, M.W., Sjödin, A., Jones, R.S., Needham, L.L., Jacobs Jr., D.R., 2010. Low dose of some persistent organic pollutants predicts type 2 diabetes: a nested case-control study. Environ. Health Perspect. 118, 1235-1242.

Lee, D.H., Steffes, M.W., Sjödin, A., Jones, R.S., Needham, L.L., Jacobs Jr., D.R., 2011. Low dose organochlorine pesticides and polychlorinated biphenyls predict obesity, dyslipidemia, and insulin resistance among people free of diabetes. PLoS One 6 (1), e15977.

Ley, S.H., Hamdy, O., Mohan, V., Hu, F.B., 2014. Prevention and management of type 2 diabetes: dietary components and nutritional strategies. Lancet 383 1999-2007.

Liem, A.K.D., Fürst, P., Rappe, C., 2000. Exposure of populations to dioxins and related compounds. Food Addit. Contam. 17, 241-259.

Lignell, S., Aune, M., Darnerud, P.O., Cnattingius, S., Glynn, A., 2009. Persistent organochlorine and organobromine compounds in mother's milk from Sweden 1996-2006: compound-specific temporal trends. Environ. Res. 109, 760-767. 
Lind, L., Lind, P.M., Lejonklou, M.H., Dunder, L., Bergman, Å., Guerrero-Bosagna, C. Lampa, E., Lee, H.K., Legler, J., Nadal, Å., Pak, Y.K., Phipps, R.P., Vandenberg, L.N., Zalko, D., Ågerstrand, M., Öberg, M., Blumberg, B., Heindel, J.J., Birnbaum, L.S., 2016. Uppsala consensus statement on environmental contaminants and the global obesity epidemic. Environ. Health Perspect. 2016 (May) .

Longnecker, M.P., Daniels, J.L., 2001. Environmental contaminants as etiologic factors for diabetes. Environ. Health Perspect. 109 (Suppl. 6), 871-876.

Männistö, S., Ovaskainen, M.L., Valsta, L. (Eds.) (2003). Finravinto 2002-tutkimus [The National Findiet 2002 Study]. National Public Health Institute, Series B3, 2003. Available at http://urn.fi/URN:NBN:fi-fe2014030615904.

Madden, A.M., Mulrooney, H.M., Shah, S., 2016. Estimation of energy expenditure using prediction equations in overweight and obese adults: a systematic review. J. Hum. Nutr. Dietetics (online early view).

Magliano, D.J., Loh, V.H.Y., Harding, J.L., Botton, J., Shaw, J.E., 2014. Persistent organic pollutants and diabetes: a review of the epidemiological evidence. Diabetes Metab. 40, 1-14.

Micha, R., Michas, G., Mozaffarian, D., 2012. Unprocessed red and processed meats and risk of coronary artery disease and type 2 diabetes-an updated review of the evidence. Curr. Atheroscler Rep. 14, 515-524.

Milbrath, M.O., Wenger, Y., Chang, C.W., Emond, C., Garabrant, D., Gillespie, B.W., Jolliet, O., 2009. Apparent half-lives of dioxins, furans, and polychlorinated biphenyls as a function of age, body fat, smoking status, and breast-feeding. Environ. Health Perspect. 117, 417-425.

Montonen, J., Knekt, P., Härkänen, T., Järvinen, R., Heliövaara, M., Aromaa, A., Reunanen, A., 2005. Dietary patterns and the incidence of type 2 diabetes. Am. J. Epidemiol. 161, 219-227.

Ngwa, E.N., Kengne, A.P., Tiedeu-Atogho, B., Mofo-Mato, E.P., Sobngwi, E., 2015. Persistent organic pollutants as risk factors for type 2 diabetes. Diabetol. Metab. Syndrome 7, 41.

Pajunen, P., Keinänen-Kiukaanniemi, S., Korpi-Hyövälti, E., Männistö, S., Niskanen, L., Oksa, H., Saaristo, T., Saltevo, J., Sundvall, J., Vanhala, M., Uusitupa, M., Eriksson, J., Peltonen, M., 2012. Ylipainon ja lihavuuden esiintyvyys tyypin 2 diabetespotilailla [prevalence of overweight and obesity in patients with type 2 diabetes in Finland, with english summary]. Suomen Lääkärilehti 67, 2621-2626.

Quetelet, L.A., 1869. Physique Sociale, vol. 2. C. Muquardt, Brussels, pp. 92.

Reaves, D.K., Ginsburg, E., Bang, J.J., Fleming, J.M., 2015. Persistent organic pollutants and obesity: are they potential mechanisms for breast cancer promotion? Endocr. Relat. Cancer 22, R69-R86.

Rignell-Hydbom, A., Rylander, L., Hagmar, L., 2007. Exposure to persistent organochlorine pollutants and type 2 diabetes mellitus. Hum. Exp. Toxicol. 26, 447-452.

Ruzzin, J., Petersen, R., Meugnier, E., Madsen, L., Lock, E.J., Lillefosse, H., Ma, T., Pesenti, S., Sonne, S.B., Marstrand, T.T., Malde, M.K., Du, Z.Y., Chavey, C., Fajas, L., Lundebye, A.K., Brand, C.L., Vidal, H., Kristiansen, K., Frøyland, L., 2010. Persistent organic pollutant exposure leads to insulin resistance syndrome. Environ. Health Perspect. 118, 465-471.

Sahlstrom, L.M.O., Sellstrom, U., de Wit, C.A., Lignell, S., Darnerud, P.O., 2015. Estimated intakes of brominated flame retardants via diet and dust compared to internal concentrations in a Swedish mother-toddler cohort. Int. J. Hyg. Environ. Health 218, 422-432.
Schecter, A., Päpke, O., Harris, T.R., Tung, K.C., Musumba, A., Olson, J., Birnbaum, L., 2006. Polybrominated diphenyl ether (PBDE) levels in an expanded market basket survey of U.S. food and estimated PBDE dietary intake by age and sex. Environ. Health Perspect. 114, 1515-1520.

Steenland, K., Calvert, G., Ketchum, N., Michalek, J., 2001. Dioxin and diabetes mellitus: an analysis of the combined NIOSH and Ranch Hand data. Occup. Environ. Med. 58, 641-648.

Suarez-Lopez, J.R., Lee, D.H., Porta, M., Steffes, M.W., Jacobs Jr., D.R., 2015. Persistent organic pollutants in young adults and changes in glucose related metabolism over a 23-year follow-up. Environ. Res. 137, 485-494.

Taylor, K.W., Novak, R.F., Anderson, H.A., Birnbaum, L.S., Blystone, C., DeVito, M. Jacobs, D., Köhrle, J., Lee, D.H., Rylander, L., Rignell-Hydbom, A., Tornero-Velez, R., Turyk, M.E., Boyles, A.L., Thayer, K.A., Lind, L., 2013. Evaluation of the association between persistent organic pollutants (POPs) and diabetes in epidemiological studies: a national toxicology program workshop review. Environ. Health Perspect. 121, 774-783.

Tuomisto, J.T., Pekkanen, J., Kiviranta, H., Tukiainen, E., Vartiainen, T., Tuomisto, J., 2004. Soft-tissue sarcoma and dioxin: a case-control study. Int. J. Cancer 108, 893-900.

Tuomisto, J., Pekkanen, J., Kiviranta, H., Tukiainen, E., Vartiainen, T., Viluksela, M., Tuomisto, J.T., 2005. Dioxin cancer risk-example of hormesis? Dose Response 3, 332-341.

Turyk, M., Anderson, H., Knobeloch, L., Imm, P., Persky, V., 2009. Organochlorine exposure and incidence of diabetes in a cohort of great lakes sport fish consumers. Environ. Health Perspect. 117, 1076-1082.

Turyk, M., Fantuzzi, G., Persky, V., Freels, S., Lambertino, A., Pini, M., Rhodes, D.H. Anderson, H.A., 2015. Persistent organic pollutants and biomarkers of diabetes risk in a cohort of great lakes sport caught fish consumers. Environ. Res. 140, 335-344.

Vartiainen, T., Saarikoski, S., Jaakkola, J., Tuomisto, J., 1997. PCDD, PCDF, and PCB concentrations in human milk from two areas in Finland. Chemosphere 34, $2571-2583$.

Vasiliu, O., Cameron, L., Gardiner, J., Deguire, P., Karmaus, W., 2006. Polybrominated biphenyls, polychlorinated biphenyls, body weight, and incidence of adultonset diabetes mellitus. Epidemiology 17, 352-359.

Wu, J.H.Y., Micha, R., Imamura, F., Pan, A., Biggs, M.L., Ajaz, O., Djousse, L., Hu, F. Mozaffarian, D., 2012. Omega-3 fatty acids and incident type 2 diabetes: a systematic review and meta-analysis. Br. J. Nutr. 107, S214-S227.

Wu, H., Bertrand, K.A., Choi, A.L., Hu, F.B., Laden, F., Grandjean, P., Sun, O., 2013. Persistent organic pollutants and type 2 diabetes: a prospective analysis in the nurses' health study and meta-analysis. Environ. Health Perspect. 121, $153-161$.

Zazpe, I., Bes-Rastrollo, M., Ruiz-Canela, M., Sánchez-Villegas, A., Serrano-Martínez, M., Martínez-González, M.A., 2011. A brief assessment of eating habits and weight gain in a Mediterranean cohort. Br. J. Nutr. 105, 765-775.

van den Berg, M., Birnbaum, L.S., Michael Denison, M., De Vito, M., Farland, W. Feeley, M., Heidelore Fiedler, H., Hakansson, H., Hanberg, A., Haws, L., Rose, M., Safe, S., Schrenk, D., Tohyama, C., Tritscher, A., Tuomisto, J., Tysklind, M., Walker N., Peterson, R.E., 2006. The 2005 World Health Organization re-evaluation of human and mammalian toxic equivalency factors for dioxins and dioxin-like compounds. Toxicol. Sci. 2006, 223-241. 